\title{
"Back at the same level as everyone else"-user perspectives on walking with an exoskeleton, a qualitative study
}

\author{
Gunn-Kristin Knudsen Thomassen ${ }^{1}$ - Vivien Jørgensen ${ }^{2}$ - Britt Normann ${ }^{3,4}$
}

Received: 12 April 2019 / Revised: 2 November 2019 / Accepted: 3 November 2019

(c) The Author(s), under exclusive licence to International Spinal Cord Society 2019

\begin{abstract}
Study design Qualitative, in-depth research interviews led by a theme-based interview guide.

Objectives To generate new knowledge regarding user experiences of standing and walking with Ekso ${ }^{\mathrm{TM}}$ (Ekso Bionics, Richmond, CA, USA).

Setting In-patient rehabilitation hospital in Norway.

Methods Systematic inductive content analyses were used, utilizing a pattern theory of self as an analytical framework Results The participants shared powerful stories, describing largely positive but also challenging emotions and perceptions, related to standing and walking with Ekso ${ }^{\mathrm{TM}}$. Four themes emerged: (1) bodily positions, possibilities and feelings, (2) reactivation of loss and hope for the future, (3) to be free and restricted at the same time, and (4) to be controlled and take control. The results indicate that both walking and using a wheelchair involve more than getting from one place to another, as fundamental aspects of being human are touched, involving facilitating a coherent understanding of the self and, on the other hand, leading to an "objectification" of the body.

Conclusions This explorative study points toward contrasts involved when using Ekso ${ }^{\mathrm{TM}}$. More studies of lived experiences with walking in Ekso ${ }^{\mathrm{TM}}$ are needed, comprising larger samples, variations in participant characteristics and diagnoses as well as contexts.
\end{abstract}

\section{Introduction}

\section{Background}

Powered exoskeletons for rehabilitation of gait or locomotion assistance are novel devices that have had a remarkable progression of development during recent decades $[1,2]$. They are currently available, albeit to a limited extent, to persons with spinal cord injury (SCI). The majority of

Gunn-Kristin Knudsen Thomassen

gunn-kristin.knudsen@sunnaas.no

1 Unit for Stroke, Sunnaas Rehabilitation Hospital, Nesodden, Norway

2 Department of Research, Sunnaas Rehabilitation Hospital, Nesodden, Norway

3 Faculty of Nursing and Health Sciences, Nord University, Bodø, Norway

4 Physiotherapy Department, Nordland Hospital Trust, Bodø, Norway individuals who live with a SCI are dependent on wheelchair for ambulation [3], however, upright posture and gait are often prioritized goals [4]. There is increased evidence for the feasibility and safety of exoskeletons $[1,2,5,6]$ and their positive impact on secondary health conditions such as spasticity, pain, range of motion, bowel, and lower urinary tract function, activities of daily living and quality of life [710]. When evaluating new interventions, it is essential to include user experiences [11, 12] as these reflections may differ from health staff perspectives [13-16]. Esquenazi et al. [17] noted that all subjects in a study of the safety and performance of the ReWalk powered exoskeleton had strongly positive comments regarding the emotional and psychosocial benefits of the use. However, no in-depth analyses of these experiences were presented. Sheldon et al. [18] have described how men with SCI may experience frustration and how they may "start hating the part of the body that is not working" [18, p. 310]. Hill et al. [19] hypothesized that overground walking with an exoskeleton could potentially lead to strong emotions varying from the extremes of euphoria to despair associated with a renewed realization of loss, and proposed an urgent need for more research from the user perspective. 
To deepen our understanding of patients' perceptions of using exoskeletons we need analytical tools that capture existential aspects related to upright posture involving identity [20-22]. We therefore turned to a philosophical position that conceives the body as the center of experience and expression (body-as-subject) while simultaneously being a biological organism (bodyas-object) [21-26]. Within this ambiguity, the body-assubject has primacy as we are orienting ourselves and interacting in the world as bodies [22, 23]. Gallagher [25] argues for an embodied understanding of self, where the various bodily capacities together form dynamic patterns that characterize the individual and constitute self. Essential concepts of relevance to our study are: body schema defined as sensory-motor capacities and habits that monitor and regulate movement and maintain body posture, sense of ownership toward body and movements, and sense of agency described as the feeling of being the initiator and in control of movement [22]. These concepts constitute the usually pre-reflective minimal experiential aspects of self, allowing us to take the body for granted and direct our attention toward the environment and the activities one participates in. In certain cases, such as when in pain, when paralyzed or when movements do not occur as planned, focus is directed toward the body, which is associated with a shift toward object status of the body [27]. Importantly, these minimal self-experiences shape the reflective aspects of self, termed body image. Body image is defined as the individual's perceptual experience and conceptual understanding of the body, the emotional attitude toward his/her own body and the stories others and I tell about me [25]. Therefore, loss of standing may affect aspects of self, the way the world is experienced and how people treat you $[20,28]$ and thus can have a major impact on social life.

\section{Aims and research question}

The aim of this study was to generate new knowledge in the field of neurological physical therapy, regarding the use of Ekso $^{\mathrm{TM}}$ (Ekso Bionics, Richmond, California, USA) asking the following research question: How do individuals with SCI experience using Ekso ${ }^{\mathrm{TM}}$ as a part of their rehabilitation program, and what are their reflections regarding this?

\section{Materials and method}

\section{Study design}

Based on the research question, qualitative, in-depth interviews in a phenomenological tradition were conducted. This tradition searches for the lived experiences of the participants. Accordingly such interviews are conversations, led by a theme-based interview guide which is open to what the participants emphasize, searching for, and uses, in-depth descriptions of complex phenomena in order to extract new knowledge [29, 30]. As replication is not part of the qualitative research method [29], the following descriptions aim to enable the reader to follow the process of producing and interpreting the data.

\section{Context of the study}

The study was conducted at a national rehabilitation hospital in Norway where Ekso ${ }^{\mathrm{TM}}$ (Ekso Bionics Holdings, USA) recently had been introduced. The physiotherapists, who performed the training (minimum two each session), were certified to use Ekso ${ }^{\mathrm{TM}}$ as part of in-patient physical therapy in patients with SCI. None of the authors were involved in the training.

Ekso $^{\mathrm{TM}}$ has three levels of independence; in FirstStep a step is initiated by a therapist pressing a button, in ActiveStep the user presses the button and in ProStep the user initiates a step by performing a predefined sideways weight shift. In addition, AdaptiveAssist can be used for those with remaining motor function, so that $\mathrm{Ekso}^{\mathrm{TM}}$ only completes the step if the user has not done it himself within a preset time.

\section{Sample and participants}

We chose a purposive sample $[29,30]$ of persons with SCI who had trained with Ekso ${ }^{\mathrm{TM}}$ and filled the criteria that they were skilled users at "ProStep" mode but still used the wheelchair as their main way of mobility after exercising with $\mathrm{Ekso}^{\mathrm{TM}}$. During the period from fall 2013 to spring 2014, only four people met the inclusion criteria, of whom three agreed to participate. Written informed consent was obtained from all participants. To protect participants' anonymity only a short description of the participants is given. The sample consists of three men of different ages (from young adult to middle aged), injury levels (lower cervical to lumbar), and severity (motor and sensory complete, AIS $^{1} \mathrm{~A}$, and motor and sensory incomplete, AIS $\mathrm{C}$ which means that motor function is preserved below the neurological level and more than half of key muscle functions below the neurological level of injury have a muscle grade less than 3 [31]) due to both traumatic and nontraumatic reasons. Time from injury until training with $\mathrm{Ekso}^{\mathrm{TM}}$ began, varied from a few months to several years. Two of the participants occasionally walked for training using a walking frame, walker or crutches.

\footnotetext{
${ }^{1}$ American Spinal Injury Association (ASIA) Impairment Scale (AIS)
} 


\section{Data collection}

The time and place for the interviews were chosen by the participants in order to make sure they felt safe and relaxed [29, 32]. The first author (GKT) performed 60-min audiorecorded interviews in Norwegian. Two were conducted at the participants' workplace and one at the participant's home. Initially the participants were invited to freely talk about the experiences and reflections on the use of $\mathrm{Ekso}^{\mathrm{TM}}$. The interview guide covered the following topics: the participants' expectations and prior knowledge of $\mathrm{Ekso}^{\mathrm{TM}}$, donning and doffing $\mathrm{Ekso}^{\mathrm{TM}}$, walking with $\mathrm{Ekso}^{\mathrm{TM}}$ and possibilities and limitations. The order of questions was adapted to the participants. They were encouraged to talk about specific situations, bring in new topics and provide rich descriptions. Paraphrasing [29] was used to ensure the understanding of their stories.

GKT performed verbatim transcription within $24 \mathrm{~h}$, supported by field notes. To ensure trustworthiness, GKT listened to the audio files several times while simultaneously reading the text. Topics that were repeated or emphasized by the participants were noted. The interview extracts presented were translated later in collaboration with all authors. Words emphasized by the participants are underscored.

\section{Data analyses}

Content analysis according to Lindseth and Norberg [33] was used, which is a systematic process aimed to disclose the latent meaning of the material. Guided by the research question and our theoretical framework, the analysis was carried out by the first (GKT) and the last author (BN) in three steps: initial reading including forming a naive understanding, structural analyses and a comprehensive understanding [33]. The two authors read the interviews separately, formulated their naive understanding of each of the interviews and discussed possible interpretations and concluded with preliminary themes. GKT did the structural analyses by identifying meaning units, which were condensed, staying as close as possible to the participants' words, and named with suitable codes. The structural analyses were revised by BN, codes from the three interviews were discussed, viewed together and organized based upon content into categories. The categories were, based on discussions and questions to each other's interpretations, named and grouped together in four themes and related subthemes.

The analysis took place through a continual shift between the three phases, which led to some changes in codes and categories during the process. The second author (VJ) served as an outsider in the final step, read all the analyzed material and questioned the interpretations. All authors contributed to the final paper.

\section{Research team and reflexivity}

All three authors are experienced clinical physiotherapists in the field of neurological rehabilitation while VJ has particularly expertize in SCI. GKT is formally trained in qualitative methods, a field that $\mathrm{BN}$ and $\mathrm{VJ}$ both have experience with. GKT and BN share an interest in phenomenological concepts that provides subjectivity to the body. VJ challenged and questioned the pre-understanding and assumptions of GKT and BN, thus improving the study's quality and trustworthiness.

\section{Results}

Through the structural analysis four themes with related subthemes were identified: (1) Bodily positions, possibilities and feelings; (a) Standing position and feelings, (b) Recognize "correct" movements, (c) Being at the same level as others, (d) Adjusting to sitting. (2) Reactivation of loss and hope for the future; (a) Hope for the future, (b) Feeling of loss, (c) Become aware of losses. (3) To be free and restricted at the same time; (a) Ekso ${ }^{\mathrm{TM}}$ on the body, (b) Ekso $^{\mathrm{TM}}$ as part of the body, (c) Feeling safe in one's own body. (4) To be controlled and take control; (a) Lack of control, (b) Controlling ones own movements, (c) Cooperation with $\mathrm{Ekso}^{\mathrm{TM}}$.

\section{Bodily positions, possibilities and feelings}

Subconsciously, when you are standing, you are back at the same level as everyone else. When you are talking with them you can look away, you can look out through the window. It (looking around) becomes more natural.

The participants contrasted standing and walking with $\mathrm{Ekso}^{\mathrm{TM}}$ to sitting in the wheelchair in which they were forced to hoist themselves, crane the neck to look out of the window and look up at other people. Standing in $\mathrm{Ekso}^{\mathrm{TM}}$ they described as a 'wow'-experience and it felt liberating to have more air around them. The participants described strong emotions connected to using $\mathrm{Ekso}^{\mathrm{TM}}$. Words like empowerment, motivation, dignity, and increased selfesteem were used frequently, and one stated that it was quite overwhelming to take a step after being told he would never walk again. Although the use of $\mathrm{Ekso}^{\mathrm{TM}}$ evoked positive feelings, none of the participants would trade the wheelchair, as it is far superior to $\mathrm{Ekso}^{\mathrm{TM}}$ in everyday life. One stated that in the wheelchair he was back in his right element, he could relax mentally. 


\section{Reactivation of loss and hope for the future}

The first weeks after I was paralyzed, I was lying in bed all the time, so (when sitting down after walking with Ekso) it was back to that feeling again: I'm actually not able to move my legs, but now it was in a sitting position. I tried to move my legs, but nothing happened and I just remembered; oh no, that's right. I knew nothing would happen; nonetheless, I was surprised (not being able to move my legs).

Even if the overall experiences with $\mathrm{Ekso}^{\mathrm{TM}}$ were positive and led to different comfortable bodily sensations like feeling warmth, increased blood circulation, release from spasms, better gastrointestinal function and increased strength and control over movements, the participants also shared challenging aspects such as the temporality of these positive sensations and being too much hassle. They all said that using $\mathrm{Ekso}^{\mathrm{TM}}$ made them realize how much they missed being able to stand and walk.

The participants hoped the robot technology would progress rapidly enabling them to wear it under their clothes and with new functions such as gyro stabilization (ability to self-correct to prevent falling) so they would be able to use it alone and climb stairs. Even if Ekso ${ }^{\mathrm{TM}}$ was viewed only as a tool for exercise, they would still like their own personal robot for exercise or standing. They hoped that robot technology would be part of community-based rehabilitation to increase availability.

\section{Being free and restricted at the same time}

I don't notice the weight when I'm standing. The skeleton weighs $20 \mathrm{~kg}$, but it's $20 \mathrm{~kg}$ of muscles, machines that help maintain an upright posture, so it's not something you think about.

Ekso $^{\mathrm{TM}}$ was described as a massive device that could feel rather tight and unnatural to wear. The participants described that they felt completely locked in it. Simultaneously this made standing and walking possible or easier and made them feel more free and loose. Being strapped to $\mathrm{Ekso}^{\mathrm{TM}}$ helped them feel secure and they knew Ekso ${ }^{\mathrm{TM}}$ would keep them standing even if they could not stand themselves. The participant with AIS grade A described that wearing Ekso ${ }^{\mathrm{TM}}$ was the first time, except from lying down, he felt stable and knew where his body was. The two participants who were able to walk with other devices contrasted it to walking with $\mathrm{Ekso}^{\mathrm{TM}}$. They told that when walking with a walker or walking frame they felt insecure and needed to carefully monitor their movements in order to keep their legs from collapsing or get tangled.

\section{To be controlled and take control}

I know that I'm not the one moving my legs, but in a way it still is! I control the machine to move my legs so in the end
I'm the one moving them but using another method. So then I know; if I move my body like this, I take a step, and if I use the momentum to get into a new step then I get into a good walk.

The participants stated that becoming a skilled $\mathrm{Ekso}^{\mathrm{TM}}$ user was a time-consuming process and it required a lot of concentration. Standing up was described as "sometimes rather brutal" and they were "forced into standing". Once the standing procedure started, they were unable to stop or reverse it, even if they experienced pain or a sudden increase in spasticity. The participants described a lack of control when standing up, even if they fully understood the instructions and prepared both mentally and by correcting the placement of assistive devices. Walking on "FirstStep" or "ActiveStep" was described as unnatural, staccato, and as if someone else had full control over their movements. One claimed that he was just there and someone else did all the work, moving him slowly. At "FirstStep" it could be difficult for three people to work as a unit, especially if neither of them fully understood their part. They all agreed that walking in "ProStep" felt better, even if they are not always in tune with $\mathrm{Ekso}^{\mathrm{TM}}$. It took time to find the right weight shift and learn to exploit the strength of the robot. If the settings (e.g. stride length and time) were wrong or changed frequently they said that it could feel like $\mathrm{Ekso}^{\mathrm{TM}}$ was too slow, and it hindered and limited their walking. When they became skilled at using Ekso ${ }^{\mathrm{TM}}$, they said it was like a robot that could read their mind and take a step at the right moment, which led to smooth and effective gait, flow and a feeling of getting somewhere. All participants described flow in the movements as important; it gave a sense of normal gait, the right pattern, the way it was supposed to be, and made walking as easy as before. This could evoke a feeling of joy, positive energy and empowerment, and bring forth a smile.

\section{Discussion}

Consistent features of the material are the participants' stories of positive experiences of standing and walking. However there were also contrasts when training with Ekso $^{\mathrm{TM}}$ : (1) the experiential differences between sitting and standing generating strong emotions and new thoughts, (2) the differences between $\mathrm{Ekso}^{\mathrm{TM}}$ as an enabler of control of movement and a restrictor.

The stories of the wheelchair as being their "right" element can be understood in the light of the ability to use the wheelchair to gain maximal functionality in everyday life. That is, the participants seemed to be en-wheeled [34] with their wheelchair strengthening their sense of agency. Still, the feeling of standing compared with sitting stuns them. Informed by Gallagher's [25] elaborations of self, we 
understand these experiences as recognition of themselves pre-injury with the former abilities for action or sense of agency $[20,22,28]$. The liberating feeling they describe when using Ekso ${ }^{\mathrm{TM}}$, (although being attached to it), compared with being locked in a wheelchair, can be due to regaining their natural, human form or expression; standing on two legs. The phrase "more air around me" used by one participant and the stories of extended view (e.g. the ability to look out the window) directs the attention to reflections concerning experienced space, which depends upon position and sensorimotor capacities. Returning to standing position leads to immediate changes in body schemas and a redefinition of what is possible to do and attend to [23] i.e. changes in sense of agency related to the environment. Feelings of improved control may lead to less frustration as previously reported to be a potential problem for individuals with SCI [18] The importance of upright posture, accompanied by euphoric emotions ("wow-I'm standing") and equal face-to-face interactions emphasized in this study aligns with previous studies $[28,35]$ and may be due to the pre-reflective aspects of self being at stake. As the capacities of the body shape our mind [22] being in a safe, dynamic standing position will influence thoughts and reflections both regarding themselves and the ones they interact with (body image) as demonstrated in our results. The strengthened outward orientation in an active upright position involves recognition of their pre-injury feeling of self.

We understand the strong reactivation of loss when the temporary positive effect wears off and realization of the fact that the paralysis remains as reactivation of loss of the pre-injury self, not just the neuromuscular and biomechanical ability to move one's legs. This, in combination with the stories of dreams and hopes for development, points to an underlying, un-uttered hope of once again being able to walk. Introduction of Ekso ${ }^{\mathrm{TM}}$ nourishes this hope, implying that high-tech devices are never value neutral [36]. Karp [37] claims that it is, to a large extent, society that facilitates walking as a prioritized goal: the wheelchair is a symbol of illness and loss, and is to be avoided at all cost. The interest, status, and resources associated with $\mathrm{Ekso}^{\mathrm{TM}}$ and other exoskeletons can thus be an expression of a life in wheelchair as inferior to life as a pedestrian. However, it could also be an expression of standing and walking as something existential for human beings as described in phenomenology $[20,22]$. Yet again, as stated by the participants, Ekso $^{\mathrm{TM}}$ is practical exercise aid, and according to Baunsgaard et al. [7] it can improve secondary health conditions, which in itself is a goal.

Perceiving Ekso ${ }^{\mathrm{TM}}$ as tight, uncomfortable or restricting, as the participants describe, can bring the body as an object into focus, out of the "taken-for-granted" state that is the normal situation [20, 27] This might influence aspects of both body schema and body image and thereby aspects of self. However, Ekso ${ }^{\mathrm{TM}}$ is also reported as being unnoticeable on the body and that it gives extra muscles. Informed by the relationship between body schema and body image we, understand this as $\mathrm{Ekso}^{\mathrm{TM}}$ has been embodied-i.e. the participants have a sense of ownership that includes both Ekso ${ }^{\mathrm{TM}}$ and the body. The robot is then included in the body schema, i.e. its properties are incorporated into one's own skills so that a unit occurs at the prereflective level. The "new" body, consisting of human and robot, possesses possibilities for action and interaction that are lost without $\mathrm{Ekso}^{\mathrm{TM}}$. The participants become free from distrust and concern directed at the body and its skills, thus affecting the emotional attitude toward the body i.e. body affect, as aspect of body image seems to be involved. The voiced hope that exoskeletons will be redesigned, as something that can be worn under the clothes, (is interesting and) should be investigated in future research.

The stories of being controlled by $\mathrm{Ekso}^{\mathrm{TM}}$ and the physical therapist reveal a big difference from being able to control ones owns movements. Ekso ${ }^{\mathrm{TM}}$ does not have a brain-machine interface, and thus does not take the intention to move into account. Still the participants describe Ekso ${ }^{\mathrm{TM}}$ as a far better "mind-reader" than the physical therapists. This could be because they themselves have learned to "read" Ekso ${ }^{\mathrm{TM}}$; learned to follow the movements and to take full advantage of the extra power the robot brings. This assumption is accentuated by the stories of how even small changes in the settings can cause them to lose the rhythm and make them having to learn to walk on ProStep all over again.

When walking the participants eventually experience that they are the ones who control the movements, and thus the sense of agency is strengthened. In theory [38], it is described how the sense of agency has a strong influence on the sense of ownership. Sense of ownership seems to be of crucial importance for the participants to experience walking with $\mathrm{Ekso}^{\mathrm{TM}}$ as easy and natural with a good flow. This seems to occur when body and robot are experienced as one unit; Ekso ${ }^{\mathrm{TM}}$ has been embodied and a new habitual body has been constructed. It seems that sense of ownership, sense of agency, and body schema are all positively influenced by training with $\mathrm{Ekso}^{\mathrm{TM}}$ and thus contributing to reorganization of the individual's body image in a completely different way than passively inflicted walking can do. Accordingly, when being forced into standing, particularly if resistance (spasticity) in the legs is strong, sense of agency as well as sense of ownership are compromised. However, when the participant's words about the need for constant focus and attention to maintain the rhythm and flow of the movements, it may indicate that $\mathrm{Ekso}^{\mathrm{TM}}$ is not stably embodied into the movement pattern-the movements are not automated. 


\section{Critical notes/limitations}

The obvious limitation of this study is the small number of participants, which implies that other participants might have brought in new elements [30, 39]. However, experiences from using Ekso ${ }^{\mathrm{TM}}$ are an underexplored field, and, the device is new, leading to few available participants. Still, knowledge from the user perspective is warranted [19] and we therefore argue for the value of this small study. The empirical material of our study comprises vivid descriptions, an element acknowledged as more important than sample size [32, 40] The analytical framework allows for interpretations and knowledge not presented in prior studies. We therefore consider this small study to provide new insights to guide clinical practice.

\section{Summary}

This study points to important aspects of using high-tech aids; which on one hand can facilitate a coherent understanding of the self and on the other hand lead to an "objectification" of the body. However, the study is explorative and more studies of lived experiences with walking in exoskeletons are needed, comprising larger samples, variations in participant characteristics and diagnoses, as well as contexts.

\section{Compliance with ethical standards}

Conflict of interest The authors declare that they have no conflict of interest.

Ethical approval The Norwegian Centre for Research Data approved the study (34619), which was performed according to the Declaration of Helsinki.

Publisher's note Springer Nature remains neutral with regard to jurisdictional claims in published maps and institutional affiliations.

\section{References}

1. Esquenazi A, Packel A. Robotic-assisted gait training and restoration. Am J Phys Med Rehabil. 2012;91:S217-27. quiz S28-31

2. Chen B, Ma H, Qin L-Y, Gao F, Chan K-M, Law S-W, et al. Recent developments and challenges of lower extremity exoskeletons. J Orthop Translation. 2016;5:26-37.

3. Harvey L. Management of spinal cord injuries. A Guide for Physiotherapists, Churchill Livingstone Elsevier, 2008.

4. Ditunno PL, Patrick M, Stineman M, Ditunno JF. Who wants to walk? Preferences for recovery after SCI: a longitudinal and crosssectional study. Spinal Cord. 2008;46:500-6.

5. Aach M, Cruciger O, Sczesny-Kaiser M, Hoffken O, Meindl R, Tegenthoff $\mathrm{M}$, et al. Voluntary driven exoskeleton as a new tool for rehabilitation in chronic spinal cord injury: a pilot study. Spine J. 2014;14:2847-53.

6. Bach Baunsgaard C, Vig Nissen U, Katrin Brust A, Frotzler A, Ribeill C, Kalke YB, et al. Gait training after spinal cord injury: safety, feasibility and gait function following 8 weeks of training with the exoskeletons from Ekso Bionics. Spinal Cord. 2018:56:106-16.

7. Baunsgaard CB, Nissen UV, Brust AK, Frotzler A, Ribeill C, Kalke YB, et al. Exoskeleton gait training after spinal cord injury: an exploratory study on secondary health conditions. J Rehabillitation Med. 2018;50:806-13.

8. Cruciger O, Schildhauer TA, Meindl RC, Tegenthoff M, Schwenkreis P, Citak M, et al. Impact of locomotion training with a neurologic controlled hybrid assistive limb (HAL) exoskeleton on neuropathic pain and health related quality of life (HRQoL) in chronic SCI: a case study (.). Disabil Rehabilitation: Assistive Technol. 2016;11:529-34.

9. Niedermeier M, Ledochowski L, Mayr A, Saltuari L, Kopp M. Immediate affective responses of gait training in neurological rehabilitation: a randomized crossover trial. J Rehabilitat Med. 2017;49:341-6.

10. Mekki M, Delgado AD, Fry A, Putrino D, Huang V. Robotic Rehabilitation and Spinal Cord Injury: a Narrative Review. Neurotherapeutics. 2018;15:604-17.

11. Campbell M, Fitzpatrick R, Haines A, Kinmonth AL, Sandercock $\mathrm{P}$, Spiegelhalter D, et al. Framework for design and evaluation of complex interventions to improve health. Br Med J. 2000; 321:694-6.

12. Lewin S, Glenton C, Oxman AD. Use of qualitative methods alongside randomised controlled trials of complex healthcare interventions. Methodol Study. 2009;339:b3496.

13. Harvey LA, Adams R, Chu J, Batty J, Barratt D. A comparison of patients' and physiotherapists' expectations about walking post spinal cord injury: a longitudinal cohort study. Spinal cord. 2012;50:548.

14. Carpenter $\mathrm{C}$. The experience of spinal cord injury: the individual's perspective-implications for rehabilitation practice. Phys Ther. 1994;74:614-28.

15. Whalley Hammell K. Quality of life after spinal cord injury: a meta-synthesis of qualitative findings. Spinal Cord. 2007; 45:124-39.

16. Kalpakjian CZ, Forchheimer M, Tate DG Chapter twenty-threeQuality of Life after Spinal Cord Injury. In: Sisto SA, Druin E, Sliwinski MM, editors. Spinal Cord Injuries. Saint Louis: Mosby; 2009. p. 537-52.

17. Esquenazi A, Talaty M, Packel A, Saulino M. The ReWalk powered exoskeleton to restore ambulatory function to individuals with thoracic-level motor-complete spinal cord injury. Am J Phys Med Rehabil. 2012;91:911-21.

18. Sheldon A, Renwick R, Yoshida K. Exploring body image and self-concept of men with acquired spinal cord injuries. Am J Men's Health. 2011;5:306-17.

19. Hill D, Holloway CS, Morgado Ramirez DZ, Smitham P, Pappas Y. What are user perspectives of exoskeleton thechnology? A litterature review. Int $\mathrm{J}$ Technol Assess Health Care. 2017; 33:160-7.

20. Straus EW. Phenomenological psychology. London: Tavistock publ.; 1966.

21. Gallagher S. Phenomenology. London: Palgrave Macmillan; 2012.

22. Gallagher S. How the body shapes the mind. Oxford: Clarendon Press; 2005.

23. Merleau-Ponty M, Landes DA, Carman T, Lefort C. Phenomenology of perception. London: Routledge; 2012.

24. Gallagher S. Complexities in the first-person perspective. Res Phenomenol. 2002;32:238-48.

25. Gallagher S, Shear J. Models of the self. Exeter: Andrews UK Limited; 2013.

26. Zahavi D. The Oxford handbook of contemporary phenomenology: Oxford, Oxford University Press; 2012. 
27. Leder D. The absent body. Chicago: University of Chicago Press; 1990.

28. Toombs S. The lived experience of disability. Hum Stud. 1995;18:9-23.

29. Kvale S, Brinkmann S. Interviews: learning the craft of qualitative research interviewing. 2nd ed. Los Angeles, CA: Sage; 2009.

30. Polit DF, Beck CT Nursing research: generating and assessing evidence for nursing practice. 9th ed. Philadelphia, PA: Wolters Kluwer Health; 2012.

31. Kirshblum SC, Burns SP, Biering-Sorensen F, Donovan W, Graves DE, Jha A, et al. International standards for neurological classification of spinal cord injury (revised 2011). J Spinal Cord Med. 2011;34:535-46.

32. Dahlberg K, Dahlberg H, Nyström M. Reflective lifeworld research. 2nd ed. Lund: Studentlitteratur; 2008.

33. Lindseth A, Norberg A. A phenomenological hermeneutical method for researching lived experience. Scand J Caring Sci. 2004;18:145-53.
34. Papadimitriou C. Becoming en-wheeled: the situated accomplishment of re-embodiment as a wheelchair user after spinal cord injury. Disabil Soc. 2008;23:691-704.

35. Poritz JMP, Taylor HB, Francisco G, Chang S-H. User satisfaction with lower limb wearable robotic exoskeletons. Disabil Rehabilit Assist Technol. 2019:1.

36. Greenfield B, Musolino GM. Technology in rehabilitation: ethical and curricular implications for physical therapist education. J Phys Ther Educ. 2012;26:81-90.

37. Karp G. Life on wheels: the A to $\mathrm{Z}$ guide to living fully with mobility issues. New York, NY: Demos Health; 2009.

38. Tsakiris M, Longo MR, Haggard P. Having a body versus moving your body: neural signatures of agency and body-ownership. Neuropsychologia. 2010;48:2740-9.

39. Malterud K. Qualitative research: standards, challenges, and guidelines. Lancet. 2001;358:483-8.

40. Malterud K, Siersma VD, Guassora AD. Sample size in qualitative interview studies: guided by information power. Qual Health Res. 2016;26:1753-1760. 